\title{
Spatial Dynamics Model for Land Carrying Capacity Prediction in Tangerang Selatan City
}

\author{
Rizky Lamonda ${ }^{1, *}$, Supriatna ${ }^{1}$, Revi Hernina ${ }^{1}$, Masita Dwi Mandini Manessa ${ }^{1}$, Yoanna Ristya $^{1}$ \\ ${ }^{1}$ Departement of Geography, Faculty of Science and Mathematic, University of Indonesia, Depok - Indonesia
}

\begin{abstract}
Tangerang Selatan is a city with the highest economic and population growth in Banten Province which makes the built-up land have high and rapid growth so that it can reduce the land carrying capacity of the city. This causes the predictions on the land carrying capacity need to be done so that the status of land carrying capacity can be detected before declining. The aim of this study is to produce a spatial dynamics model of land carrying capacity in Tangerang Selatan City. This study uses population data of 2008-2018, Landsat 5 TM (2008) images, and Landsat 8 OLI images (2013 and 2018). The land carrying capacity is predicted from 2008-2100 using the system dynamics model method based on the relationship between land requirements based on population growth and land availability based on built-up land, which then converted to spatial to see the spatial distribution with spatial dynamics model method. Research shows that in 2026 the land carrying capacity in Tangerang Selatan City has reached 30\% and in 2056 the land carrying capacity has been exhausted.
\end{abstract}

Keywords: Land Carrying Capacity; System Dynamics; Spatial Dynamics.

\section{Introduction}

Changes in land use are a result of interactions between humans and land [1]. High land use change in an area, shows the increasing human needs in the region [2]. Where the increase in human needs is always related to the population growth and development activities [3].

High development activities encourage changes in land use significantly and affect the balance between humans and the environment [4]. When the land needs to increase and land availability decreases, the land carrying capacity will also decrease [5]. Land carrying capacity is a comparison between the land availability and land needs [6]. Land availability described by open space and land needs to be described by built-up area.

Urban areas are the central areas of population growth and development which if not planned properly can have a negative impact especially for the land and water carrying capacity [7]. Urban areas are the key to world sustainability because urban areas affect the development of the surrounding environment, and the development of the environment will also affect the development of urban areas [8]. Therefore, the use and efficiency of urban land use must be improved based on rational land use planning with the aim of sustainable development [9].

One of the keys to sustainable development in urban areas is planning and spatial planning especially in the development of green open spaces [7, 2]. The Spatial Dynamics model in these problems can describe both land use changes and their impact on environmental factors, and the socio-economic factors around them, and can accurately predict future areas and spatial patterns of land use changes that can be used as consideration by the government in development planning [10].

The city of South Tangerang has the highest economic growth in Indonesia, which amounted to $7.43 \%$ in 2017 supported by a population of 1.5 million with a productive age of almost $75 \%$ of the total population. The population growth rate in South Tangerang City in 2017 has a rate of $3.21 \%$ and is the highest population growth rate in Banten province [11]. High economic development and population growth tend to encourage changes in land use as a form of urbanization and industrialization [12].

South Tangerang City according to the City Planning in 2011 had open space of 46.53\% [13], which according to Ministry of Publik Works Regulation Number $05 / \mathrm{PRT} / \mathrm{M} / 2008$, the minimum area of open space is $30 \%$ of the total area. It aims to preserve the carrying capacity of existing land and as a form of sustainable development. So that the future development of land carrying capacity in the City of South Tangerang must be planned and predicted using a spatial dynamics model so as not to exceed a minimum area of $30 \%$. Based on that, the aim of this study is to produce a model of spatial dynamics of land carrying capacity in Tangerang Selatan City.

\section{Methods}

This research was conducted in South Tangerang City, Banten Province which has high population growth and

\footnotetext{
* Corresponding author: rizky.lamonda@ui.ac.id
} 
high built-up area development. Spatial Dynamics is a mixed method between System Dynamics and Geographic Information System (GIS) and is the right way to explain the relationship between the population, the built-up area and the land carrying capacity in the future [6]. System Dynamics was used to predict the population and built-up area in the future and Geographic Information System (GIS) to simulate the prediction from System Dynamics to spatial.

In this study, there were two categories of a variable, which was System Dynamics Variable and Spatial Dynamics Variable. System Dynamics variable contains 19 variables, such as population, land needs, land availability, and built-up area. Population and land needs were obtained from population data of 2008-2018. Meanwhile, land availability and built-up area were obtained from Landsat 5 TM image (2008), and Landsat 8 OLI Image (2013 and 2018). The system dynamics step to create the causal loop diagram was determined by former with a model used and assumption variable. This method could be simulated with a spatial concept, by looking at to time and direction of built-up area development using GIS.

Spatial Dynamics contains 5 variables, such as slope, distance from the river, distance from the road, distance from the economic center, and limitation area. Those spatial variables were processed using an overlay method to make a built-up suitability area to simulate the direction of built-up area development in the future. Data processing and analysis of System Dynamics using System Dynamics Software, meanwhile the GIS using ArcGIS 10.6.1. software.

The GIS analysis used overlay analysis with its results such as a very suitable area, suitable area, and not a suitable area for built-up area. This spatial analysis combined with system dynamics analysis result on the development of built-up area (settlement) with the existing availability land.

\section{Result and Discussions}

\subsection{System Dynamics Model}

System Dynamics are models in the form of relationships between all parts of a system and how these relationships affect the system over time [14]. According to the background on modeling issues as a story, a model variable, and an assumption, then made a Causal Loop Diagram (CLD) from the model of land availability and built-up area that showed in Figure 1.

According to Figure 1, the Causal Loop Diagram of the land carrying capacity model consists of five feedbacks, which is two negative feedbacks and three positive feedbacks. Those feedbacks are population amount increases, then the population growth will increases. Population growth increase, then the population amount will also increase. Population amount increases, then the mortality (population decrease) will increase. Conversely, if mortality (population decrease) increase, then the population amount will decrease.

Population amount increases, then the land demand will also increase. Land demand decreases, then the land carrying capacity decrease. Land carrying capacity decrease, then the population pressures increasing. Population pressures increase, then the pressures factor of migration out will increase. Migration out (emigration) increase will cause the population to decrease which population amount will decrease eventually.

The built-up area increasingly widespread, then the built-up area pressure factor also increasingly widespread, so the built-up area growth rate increasingly fast. The built-up area increasingly widespread, eventually. Built-up area increasingly widespread causing a built-up area growth rate increasingly fast.

According to Causal Loop Diagram (CLD), system dynamics model for land carrying capacity, then the next is made Stock and Flow Diagram (SFD), that is showed in Figure 2.

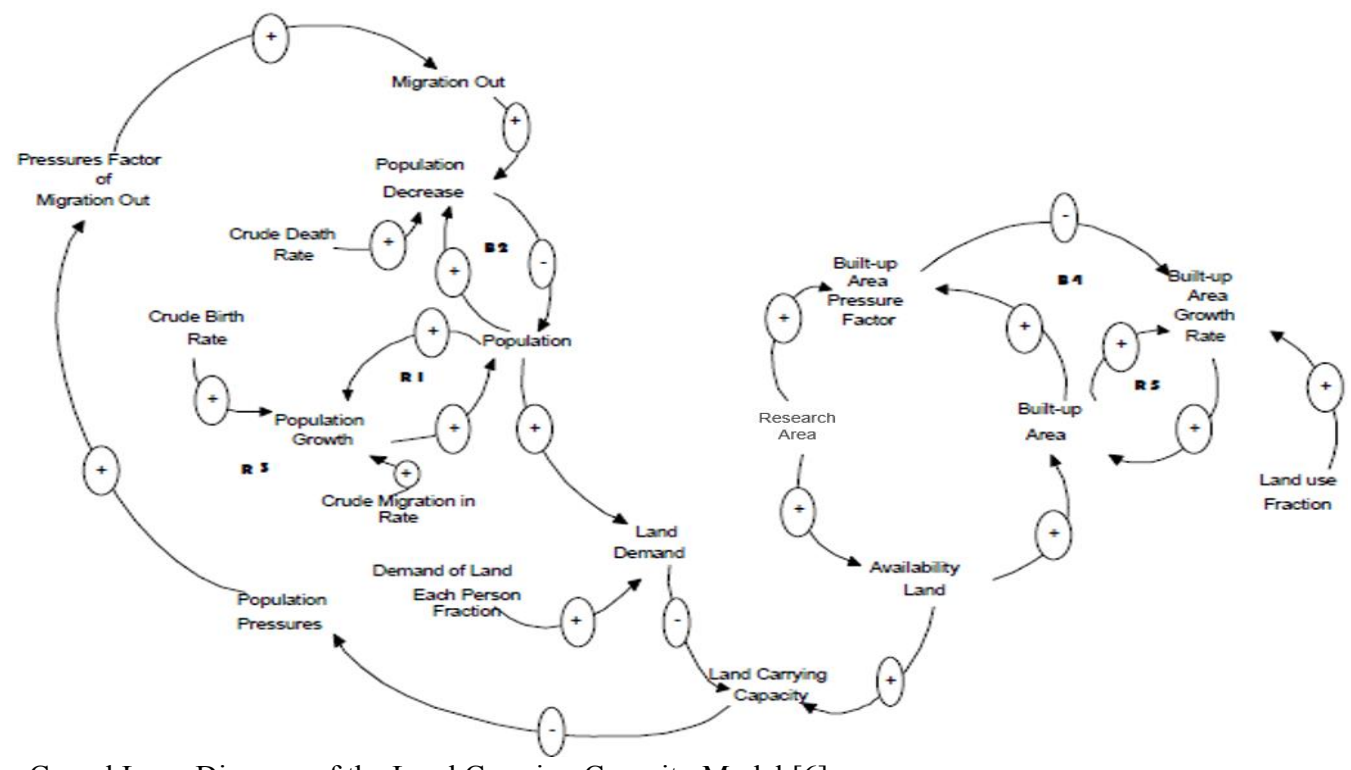

Fig. 1. The Causal Loop Diagram of the Land Carrying Capacity Model [6] 


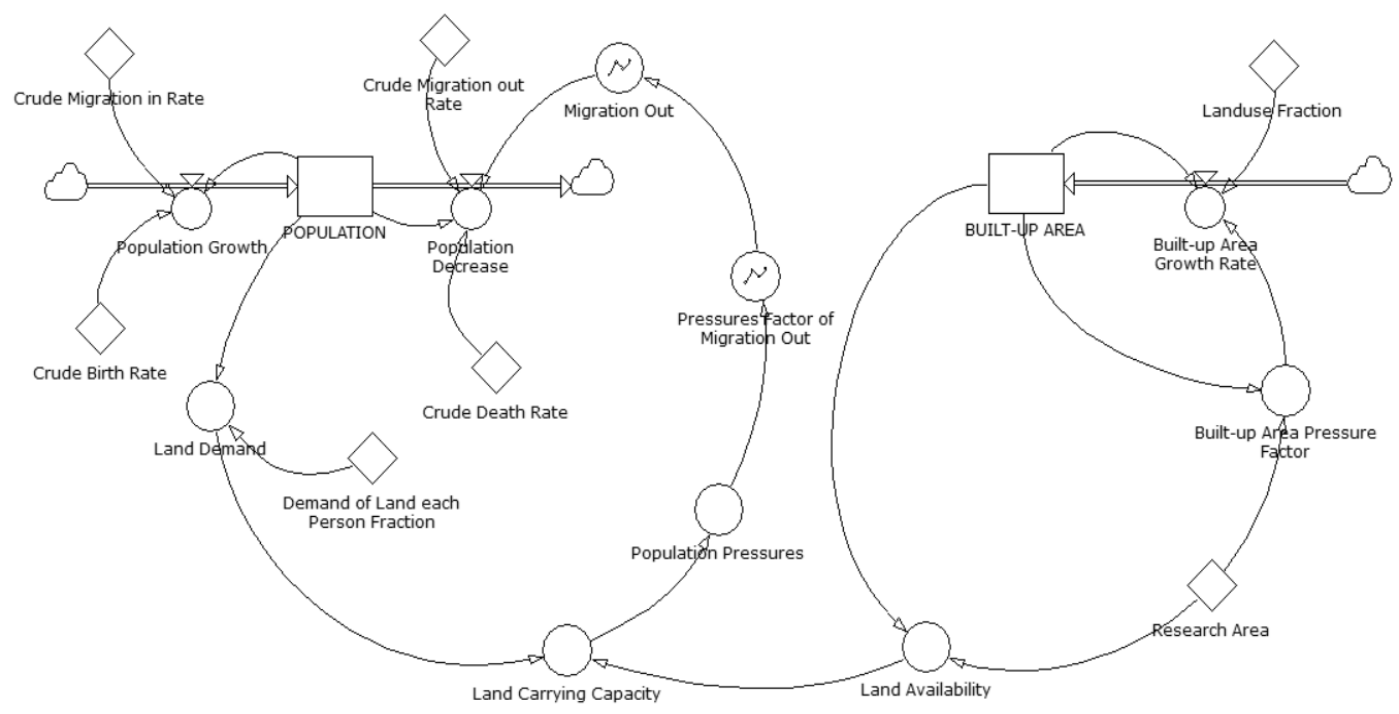

Fig. 2. Stock and Flow Diagram (SFD) System Dynamics Model for Land Carrying Capacity

\subsection{Dimensional Consistency Analysis}

Dimensional Consistency Analysis has the shape of variable and dimension that be obtained from Stock and Flow Diagram (SFD) of land carrying capacity model as follows:

- stock Population=1076302 $<<$ Person $>>$

- stock Built-up Area=7334<<ha $>>$

- aux Land Carrying Capacity='Availability Land'/'Land Demand'

- aux Availability Land="-'Built-up Area'

- aux Built-up Area Pressure Factor='Built-up Area'/" flow Built-up Area Growth Rate=('Built-up Area'*'Land use Fraction')*(1-'Built-up Area Pressure Factor')

- flow Population Growth=(Population*'Crude Birth Rate')+(Population*'Crude Migration in Rate')

- flow Population Decrease $=($ Population*'Crude Death Rate')+('Crude Migration out Rate'*'Migration Out'*Population)

- Constanta Crude Migration out Rate $=0.17<<\% /$ year $>>$

- Constanta Crude Death Rate $=0.07<<\% /$ year $>>$

- aux Demand of Land each Person Fraction= $0.0025<<$ ha/Person $>>$

- Constanta Crude Migration in Rate $=2.47<<\% /$ year $>>$

- Constanta Crude Birth Rate $=2.50<<\% /$ year $>>$

- aux Population Pressures $=1 /$ 'Land Carrying Capacity'

- Constanta Research Area $=16466.485433<<$ ha $>>$

- Constanta Land use Fraction=5.8<<\%/year $>>$

- aux Migration Out $=$ GRAPH('Migration out Pressure Factor', $0,1,\{0.06,0.29,5 / / \operatorname{Min}: 0 ; \operatorname{Max}: 5 / /\})$

- aux Pressures Factor of Migration Out $=$ GRAPH('PopulationPressures', $0,1,\{0.29,0.32,0.34$ ,0.37,0.39,0.43,0.46,0.50,0.54,0.59,0.64,1//Min:0;Max: $1 / /\})$

- aux Land Demand = Population*'Demand of Land each Person Fraction'

\subsection{Model Validation}

The validity of model performance to gain confidence that the model performance appropriate with the performance of real system is to compare between the model output and the empirical data, then do the statistical test to see the deviation with Average Mean Error (AME) that is the deviation accepted is $<30 \%$, due to many factors that cannot be controlled on the model [6].

Table 1. Actual and Simulation of Population

\begin{tabular}{|c|l|c|}
\hline \multicolumn{3}{|c|}{ Population (People) } \\
\hline Year & Actual & Simulation \\
\hline 2008 & $1,076,302$ & $1,076,302$ \\
\hline 2009 & $1,108,943$ & $1,128,805$ \\
\hline 2010 & $1,298,504$ & $1,183,869$ \\
\hline 2011 & $1,346,102$ & $1,241,619$ \\
\hline 2012 & $1,394,405$ & $1,302,186$ \\
\hline 2013 & $1,443,403$ & $1,365,706$ \\
\hline 2014 & $1,492,999$ & $1,432,325$ \\
\hline 2015 & $1,543,209$ & $1,502,192$ \\
\hline 2016 & $1,593,812$ & $1,575,468$ \\
\hline 2017 & $1,644,899$ & $1,652,316$ \\
\hline 2018 & $1,696,363$ & $1,732,912$ \\
\hline Average & $1,421,722$ & $1,381,246$ \\
\hline
\end{tabular}

In Table 1, the actual and simulation population starts in 2008 until 2018 to get the average. It can be seen that the average actual population obtained is $1,421,722$ people, while the average simulation population is $1,366,535$ people. The average is then used to validate the model using AME between the actual population and the simulation, so as to produce an AME value of $2.85 \%$ whose trend can be seen in figure 3 . The results of the validation test of the population using AME stated that the model for the population could be used for prediction. 


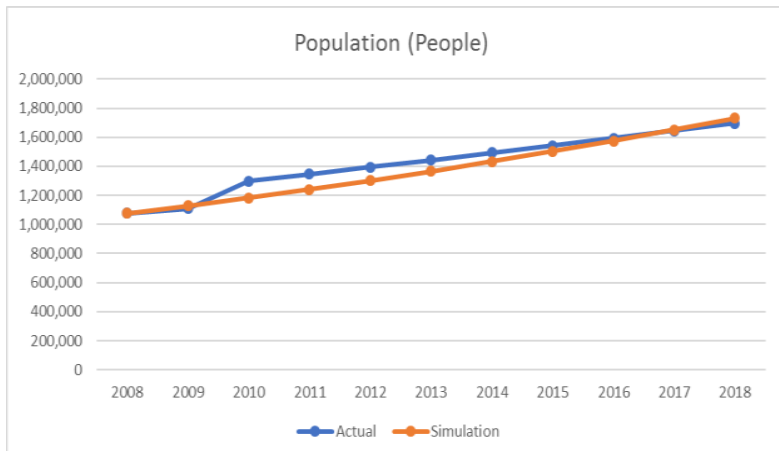

Fig. 3. Actual and Simulation of Population, $\mathrm{AME}=2.85 \%$

In addition to the population, the built-up area was also tested for model validation. The actual built-up area is obtained from Landsat $5 \mathrm{TM}$ and Landsat 8 image. Based on Table 2, it can be seen that the average actual area of land built is $9031.05 \mathrm{Ha}$, while the average area of land constructed by the simulation is $8521.23 \mathrm{Ha}$. Based on these averages, the AME obtained from the simulation of the area of built-up land is $5.65 \%$, the trend can be seen in Figure 4. Based on the results of the AME, the built-up area model is stated valid and could be used for prediction.

Table 2. Actual and Simulation Built-up Area

\begin{tabular}{|c|c|c|}
\hline \multicolumn{3}{|c|}{ Built-up Area (Ha) } \\
\hline Year & Actual & Simulation \\
\hline 2008 & 7333,99 & 7334,99 \\
\hline 2009 & 7759,83 & 7569,92 \\
\hline 2010 & 8185,67 & 7807,13 \\
\hline 2011 & 8611,51 & 8045,25 \\
\hline 2012 & 9037,35 & 8283,89 \\
\hline 2013 & 9463,20 & 8522,65 \\
\hline 2014 & 9572,13 & 8761,12 \\
\hline 2015 & 9681,06 & 8998,90 \\
\hline 2016 & 9789,99 & 9235,60 \\
\hline 2017 & 9898,92 & 9470,82 \\
\hline 2018 & 10007,85 & 9704,19 \\
\hline Average & 9031,05 & 8521,23 \\
\hline
\end{tabular}

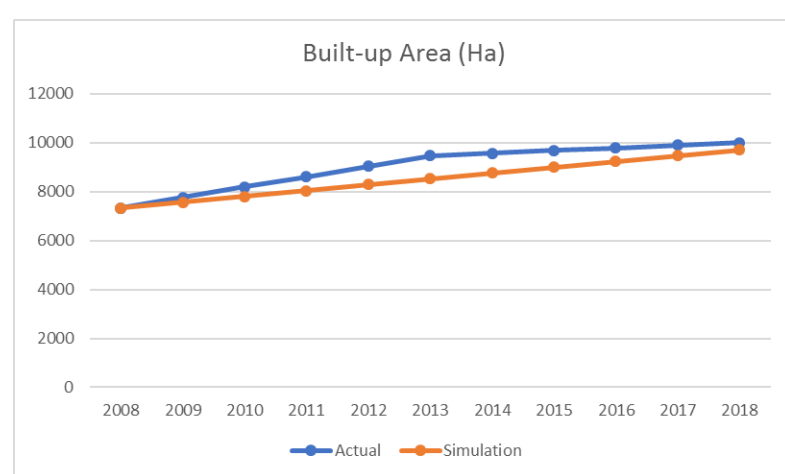

Fig. 4. Actual and Simulation of Built-up Area, AME $=5.65 \%$

\subsection{Model Simulation}

After the model is stated valid, the model can be simulated. The following Line Graph illustrated the simulation result of population and built-up area is shown on Figure 5 and Figure 6.

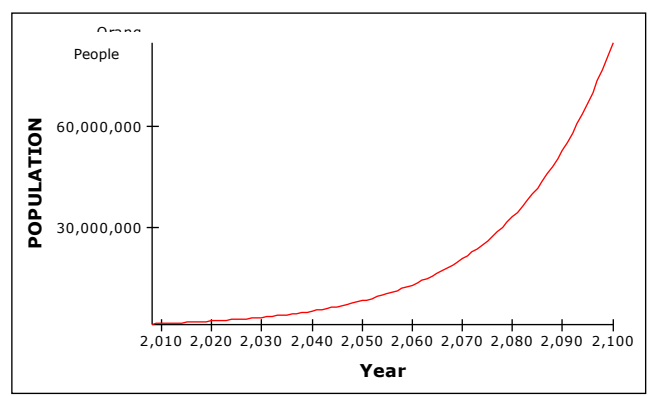

Fig. 5. System Dynamics Simulation Result of Population

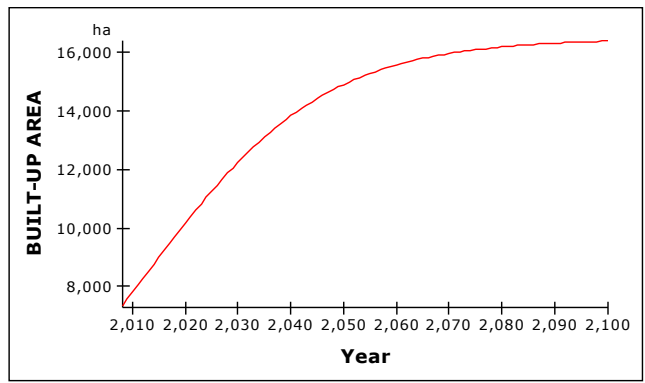

Fig. 6. System Dynamics Simulation Result of Built-Up Area

Population growth and built-up land are simulated until 2100 to determine trends of these two variables. Based on the simulation results up to the year 2100. it can be seen in Figure 5 that the population experiences exponential growth where the longer the growth will be higher. Whereas the land built on Figure 6 has experienced a logarithmic development where its development is getting smaller or slower because of the limited availability of land in the form of open space.

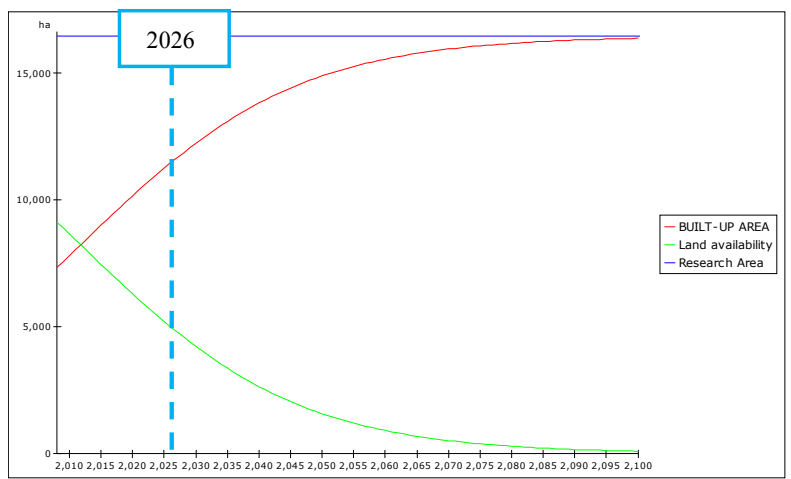

Fig. 7. System Dynamics Simulation Model of Relationship between Built-up Area and Land availability up to year 2100

The relationship between land availability (green line) and built-up land (red line) basically has the same pattern but is inversely proportional, but the area of both will not exceed or less than the area of research (blue line) which is $16,466 \mathrm{Ha}$ (see figure 7). Based on the relationship between the availability of land and built-up land, it was also found that in 2026 the land built had 
approached the land carrying capacity threshold of $70 \%$ $(11,526.54 \mathrm{Ha})$ of the total area with population of 2.536 .490 people, so that by 2026 there was a need action to slow or stop the development of land built so that the carrying capacity of land can be sustainable. In addition, it can also be seen that by the year 2100, the availability of existing land is almost gone, as well as the built-up area has almost approached the maximum area of the research area.

\subsection{Suitability Area for Built-up Land}

In developing a built-up area, humans tend to choose areas that are most suitable. The area of land suitability is built limited to physical conditions and accessibility conditions of a region. The physical condition variable used in this study is the condition of the slope and the distance from the river. While the accessibility condition variables in this study used are the distance from the road, and the distance from the center of economic activity. The physical condition and accessibility then processed with overlay method to produce suitability area for built-up land with a category of very suitable, suitable, and unsuitable.

Regions that have the category of very suitable for built-up area are assumed to be the region that must be chosen as the main choice in development of built-up area. Regions that have the category of suitable are assumed to be the second choice in the development of built-up area. Last, area that have the category of unsuitable are assumed can't be developed to built-up area.

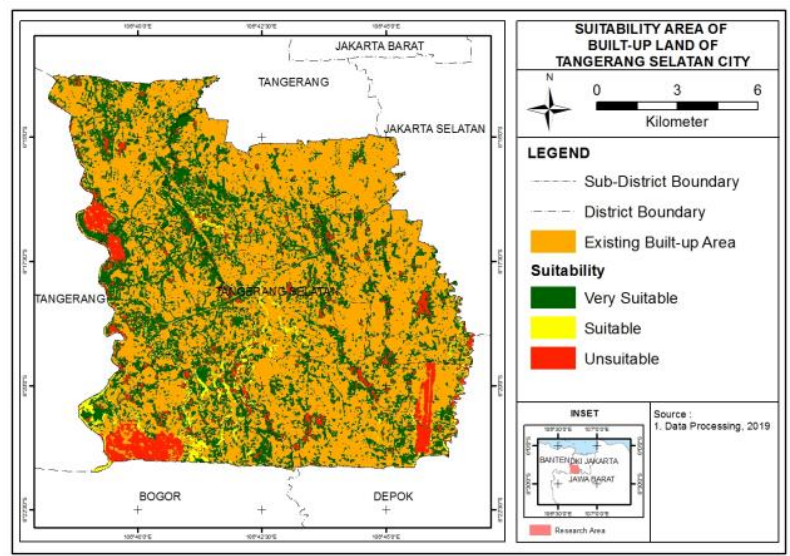

Fig. 8. Suitability Area of Built-up Land of Tangerang Selatan City

Based on the results of the Suitability Area of Builtup Land on Figure 8, it can be seen that the area of suitability that dominates South Tangerang City is an area with a category of very suitable, while areas with category of unsuitable tend to follow the built-up limitation area, and areas with category of suitable are relatively less than category of very suitable and unsuitable.

\subsection{Discussions}

Based on the results of the System Dynamics model of land carrying capacity in the Tangerang Selatan City, it was found that the built-up land was close to the safe threshold of land carrying capacity with an area of 70\% $(11,526.54 \mathrm{Ha})$ of the total research area in 2026 with a population of 2,536,490 people. This means that the area of land built has increased by 1518.7 hectares and the total population is 840,126 in 2026 compared to 2018 (existing). The prediction of the distribution of built-up land in 2026 based on the area of conformity can be seen in Figure 9.

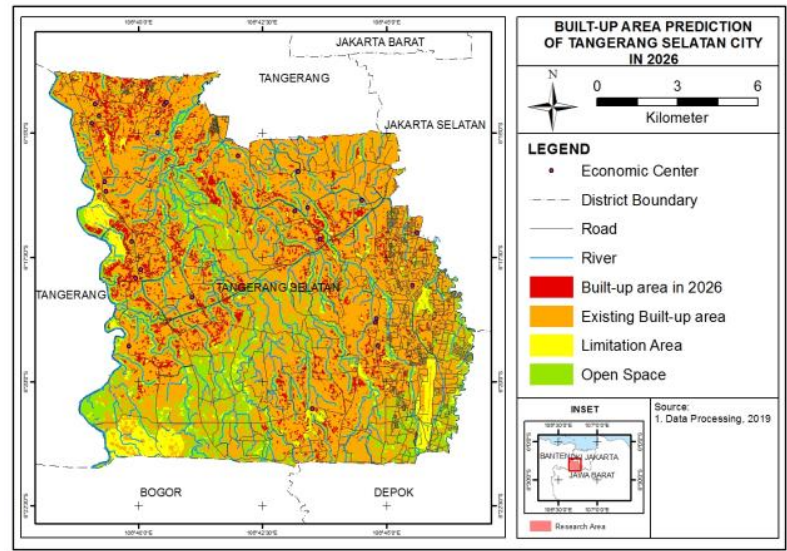

Fig. 9. Built-up Area Prediction of Tangerang Selatan City in 2026

The prediction of the distribution of built-up area in 2026 in Tangerang Selatan City is based on the area that is most suitable for the land to be built first. This makes the pattern of the spread of built-up land in 2026 tending to still spread to areas with the most ideal conditions for land to be built, such as being far from the river, flat slope, close to the road, and close to the economic center. However, the influence of the spread of land built-in 2026 tended to be more influenced by the river and the center of economic activity. Whereas the road network is not very influential because almost all parts of the research area have good road networks. This causes the pattern of development of built-up land in 2026 which tends to occur mostly in research areas that have fewer and more distant river networks, as well as a relatively considerable amount of economic center.

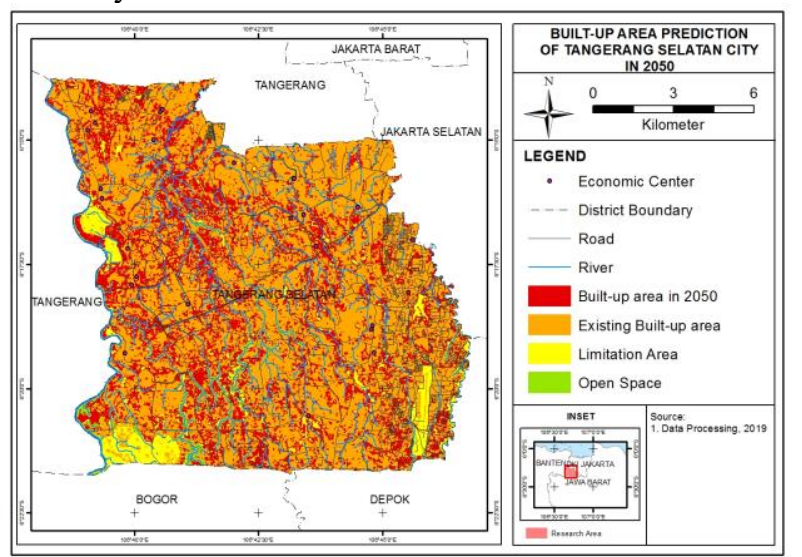

Fig. 10. Built-up Area Prediction of Tangerang Selatan City in 2050

In the year 2050, the simulation results show that regions with a very suitable degree of land suitability have been exhausted and have begun to develop according to the degree of land suitability that is suitable. 
According to the prediction of the dynamic system model, in 2050 the area of land that was built in the study area had an area of $14,915.35$ ha or $90.5 \%$ of the total area (see Figure 10) with a population of 7,945,178 inhabitants. This means that the carrying capacity of the research area in 2050 is already reaching the land carrying capacity threshold and makes land in the research area no longer optimal in meeting the land needs of the people who live in it.

Based on the distribution of built-up area in 2050 from the results of the prediction, It can be seen that most of the available open space has become built-up area. Open spaces that are still available in the research area only exists in suitable degree of suitability area for built-up area which basically has less ideal conditions for the land to be built itself than the very suitable area. Based on this, the available land is generally only $2.7 \%$ of the total area of research that can be utilized outside of the limited area of built-up area.

The simulation results show that in 2056, suitable are of suitability degree of built-up area had been used up. This means that the land carrying capacity in Tangerang Selatan City in 2056 has run out because it cannot provide more land for human needs in it. According to the prediction of the System Dynamics model, in 2056 the area of land that was built in the study area had an area of $15,373.36$ hectares or $93.2 \%$ of the total area with a population of $10,556,784$ people.

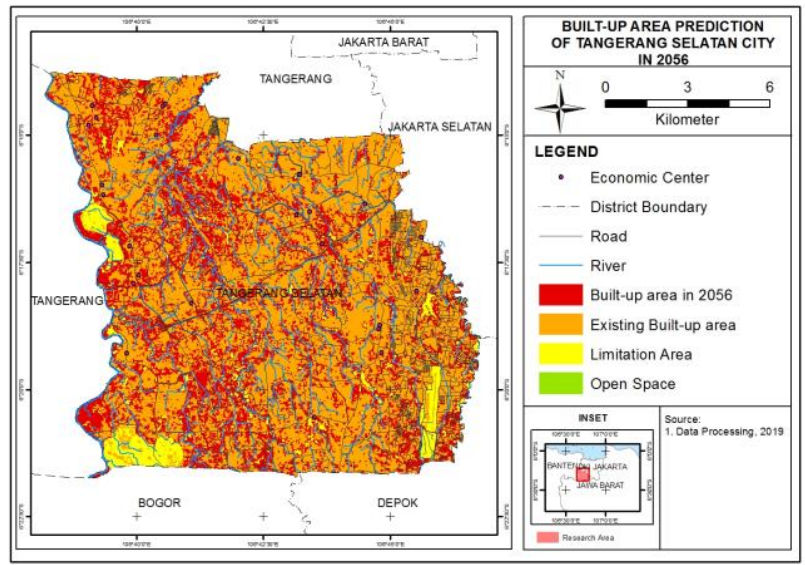

Fig. 11. Built-up Area Prediction of Tangerang Selatan City in 2056

It can be seen that the distribution of land built by predicted results in 2056 has occupied all open spaces in the research area (see figure 11). The remaining open spaces are only a limitation area and an area that is not suitable for land to be built. This makes no further development of land built in the year after.

\section{Conclusion}

The System Dynamics model of the land carrying capacity of Tangerang Selatan City shows that the land carrying capacity of the Tangerang Selatan City reaches its safe limit (30\% of open space and $70 \%$ of built-up area) in 2026 . In the year 2056, it is predicted that open space that can be used as built-up area will be exhausted outside of the limitation area so that in the following year the built-up land cannot develop again. The development of built-up area based on spatial dynamics prediction models tends to be more influenced by rivers and economic center, while the road network is less influential because the Tangerang Selatan City has a good road network and slope is also less influential due to Tangerang Selatan City generally has a flat slope condition.

Gratitude is addressed to Geography Departement University of Indonesia which has supported this research.

\section{References}

1. H. Zhang, X. Liao, T. Zhai, Elsevier: Phys. and Chem. of the Earth, 104, 58-65 (2017)

2. W. Brontowiyono, R. Lupyanto, B. Sulistiono, D. A. Harjito, J. Hamidin, E. Hapsari, M. Yasin, C. Ellinda, Procedia Env. Sci., 28, 519-527 (2015)

3. N. A. Pratama, B. R. Widiatmono, R. Wirosoedarmo, Jurnal SDA dan Lingkungan, 2, 1 (2015)

4. C. $\mathrm{Ku}$, Elsevier : Applied Geography, 69, 1-9 (2016)

5. A. Asfari, Supriatna, N. Rizkyhandari, IRWNS, 8 (2017)

6. Supriatna, J. Supriatna, R. H. Koestoer, N. D. Takarina, Procedia: Soc. and Behav. Sci., 227, 1930 (2016)

7. S. Patra, S. Sahoo, P. Mishra, C. Subhash, Elsevier: J. of Urban Management, 7, 70-84 (2018)

8. M. Pacione, Third Edition: Urban Geography-A Global Perspective (Routledge, New York, 2009)

9. G. Tian., B. Ma, X. Xu, X. Liu, L. Xu, X. Liu, L. Xiao, L. Kong, Elsevier: Ecological Indicator, 70, 439-450 (2016)

10. X. Xu, Z. Du, H. Zhang, Elsevier: Inter. J. of Applied Earth Observ. and Geoinformation, 52, 568-579 (2016)

11. Badan Pusat Statistik, Kota Tangerang Selatan dalam Angka Tahun 2018 (Badan Pusat Statistik, Tangerang Selatan, 2018)

12. M. K. Jat, M. Choudary, A. Saxena, Elsevier: The Egyptian J. of Remote Sensing and Space Sci., 20, 223-241 (2017)

13. L. Y. Iriani, Jurnal Sosial dan Pekerjaan Umum, 20 (2016)

14. A. Ford, Modelling the Environment (Island Press, Washington D.C., 1999) 